\title{
Chile: Una prosperidad no democrática MARTA LAGOS
}

\section{Resumen}

Se argumenta que tanto en el caso latinoamericano en general como en el chileno en particular, el aumento en la prosperidad no implica una secularización equivalente a la que experimentaron las sociedades del primer mundo con el crecimiento económico. Hay una tensión entre la modernidad y el tradicionalismo, entre el progreso y las costumbres. Esto genera una aceptación de ciertos beneficios de la modernidad, pero la racionalidad queda postergada, apareciendo sustitutos de ella como la tecnocracia. Todo lo anterior lleva, en Chile, a una democratización limitada. De este modo, el aumento del ingreso proporciona beneficios personales a cada cual, sin que se traduzca en beneficios colectivos equivalentes. Esta prosperidad individual y -en cierta medida- no democrática consolida la desconfianza. Por su parte el proceso de cambio valórico ha sido lento, medido por la velocidad de los últimos 16 años. A esa velocidad , Chile se demorara unos 30 a 40 años en alcanzar el promedio de valores de las sociedades europeas más prósperas. Resulta interesante, en ese contexto, que los valores asociados al libremercado van en disminución, a pesar de los niveles de crecimiento mostrados en los últimos años. Ello ocurre porque en una sociedad donde la prosperidad no es democrática, el acceso al mercado es limitadopara muchos. Por tanto, la noción de 'prosperidad no democrática' es la mejor manera de expresar el punto de desarrollo en que se encuentra Chile en el año 2007.

\begin{abstract}
It is argued that in the Latin American case in general, and in the Chilean case in particular, growth in prosperity does not imply an equivalent secularization like the one experimented by the first world in economical growth. There is tension between Modernness and Traditionalism, between progress and costumes. This generates acceptance of certain benefits of modernness, but rationality is postponed, thus emerging substitutes of it, like technocracy. All which have been mentioned, leads us in Chile to a limited democracy. In this way, the growth of income gives personal benefits to each without any equivalent collective benefit. This individual - and in a sense, not democratic - prosperity consolidates distrust. On the other hand, the process of change of values has been slow, measured by the speed of the last 16 years. At this speed, Chile will take 30 or 40 years to reach the average of values in most prosperous European societies. It is interesting, in that context, that the values associated to free market are decreasing, regardless of the levels of growth shown in the last years. This occurs because in a society where prosperity is not democratic, the access to market is limited for many. Therefore, the notion of "non democratic prosperity" is the best way to define the point of development in which Chile is in 2007.
\end{abstract}

\section{Introducción}

Observamos Chile desde una perspectiva comparada, no para medirnos contra nosotros mismos, sino a la luz de la evolución de otras sociedades.

Desde Karl Marx a Daniel Bell, los teóricos de la modernización han argumentado que el desarrollo económico trae consigo cambios culturales inminentes. Otros desde Max Weber a Samuel Huntington han dicho que los valores culturales tienen una influencia autónoma en la sociedad. La Encuesta Mundial deValores pone 
a prueba la hipótesis que el desarrollo económico está ligado a cambios sistemáticos en valores básicos. Usando los datos de 65 sociedades que representan al 75\% de la población del mundo, encontramos evidencia de ambas. Tanto, cambios culturales masivos como persistencia de tradiciones culturales distintivas en sociedades y grupos de sociedades.

El estudio da cuenta de la existencia de sociedades que desmienten más que confirman "una teoría" de la modernización. La persistencia de conjuntos homogéneos de valores en conjuntos homogéneos de países, niega la teoría de Marx, al mismo tiempo que el cambio sistemático producido por el desarrollo económico la confirma. En América Latina, cada país tiene "su modernización".

Chile tiene un desarrollo marcado por el catolicismo y su historia específica y sin embargo sus valores cambian principalmente hacia mayores grados de individualismo a medida que aumenta su nivel de bienestar.

En efecto, Max Weber pudo comprobar que los factores económicos y tecnológicos del desarrollo no eran dominantes, sino uno de las fuerzas que modelan la historia de los pueblos. Las otras fuerzas son: los valores, la moral, los compromisos, los hábitos, la cultura. El desarrollo de la sociedad, no puede ser entendido ni cambiado sin prestar atención a esas facetas normativas. Este estudio es totalmente weberiano en ese sentido. Intenta lo que han intentado los cientistas sociales desde su inicio, entregar una explicación sobre los motivos que conducen a los comportamiento de los hombres, considerando la tensión entre los motivos individuales de cada persona, y los motivos sociales del bien colectivo. ¿Cuáles valores, hábitos, cultura nos impulsan al desarrollo y la modernidad, cuales nos retienen? Es por ello que son los poetas y literatos los que mejor saben reflejar sus sociedades, como bien dijo Octavio Paz, "ellos quieren la perfección mientras nosotros queremos la redención"1.

En efecto, la racionalidad como meta última de un desarrollo valórico de las sociedades del primer mundo, tiene una acogida relativa en nuestras sociedades profundamente católicas que se secularizan con lentitud. Nuestras sociedades parecen a veces querer abrazar sólo las características más luminosas de la modernidad, que entregan oportunidades, desechando las más oscuras, aquellas que intenta destruir y cambiar, que hoy se identifican tan claramente. Lo más interesante es, por tanto, aquello más resistente al cambio.

El mapa cultural del mundo 2005-2006 logra identificar conjuntos de valores que

Octavio Paz, El laberinto de la soledad. 2 El Estudio Mundial de valores es una encuesta comparada que se aplica desde 1980 cada cinco años a unas
75 sociedades que representan con muestras representativas de la población de cada país, el $70 \%$ de la población del mundo. Las muestras tienen al menos 1000 entrevistas por país, con un margen de error del 3\% por país. El cuestionario es idéntico para todos los países. www.worldvaluesurevy.net. Los datos están disponibles al público en general. 
dominan en conjuntos de países/zonas geográficas, pudiéndose medir el sentido y velocidad de cambio de ellas.

\section{MAPA CULTURAL DEL MUNDO}

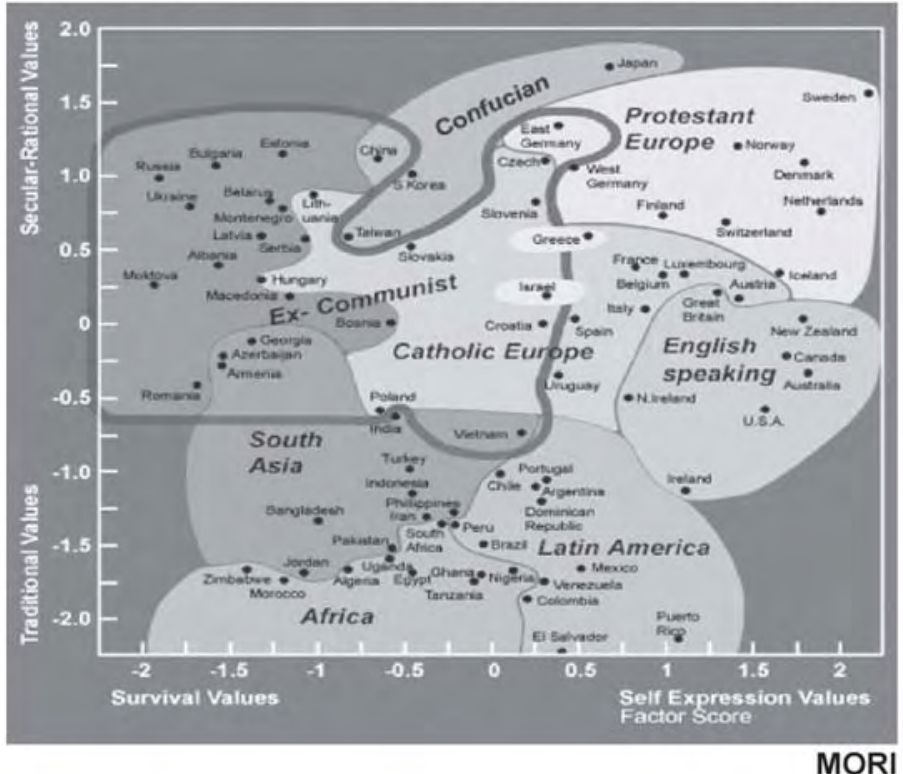

El modelo refleja como el mundo se ha ido desplazando valóricamente en una polaridad entre la restricción y la elección en dos dimensiones: el espectro de los valores de la Supervivencia/Autoexpresion, y el espectro de valores tradicional/seculares racionales.

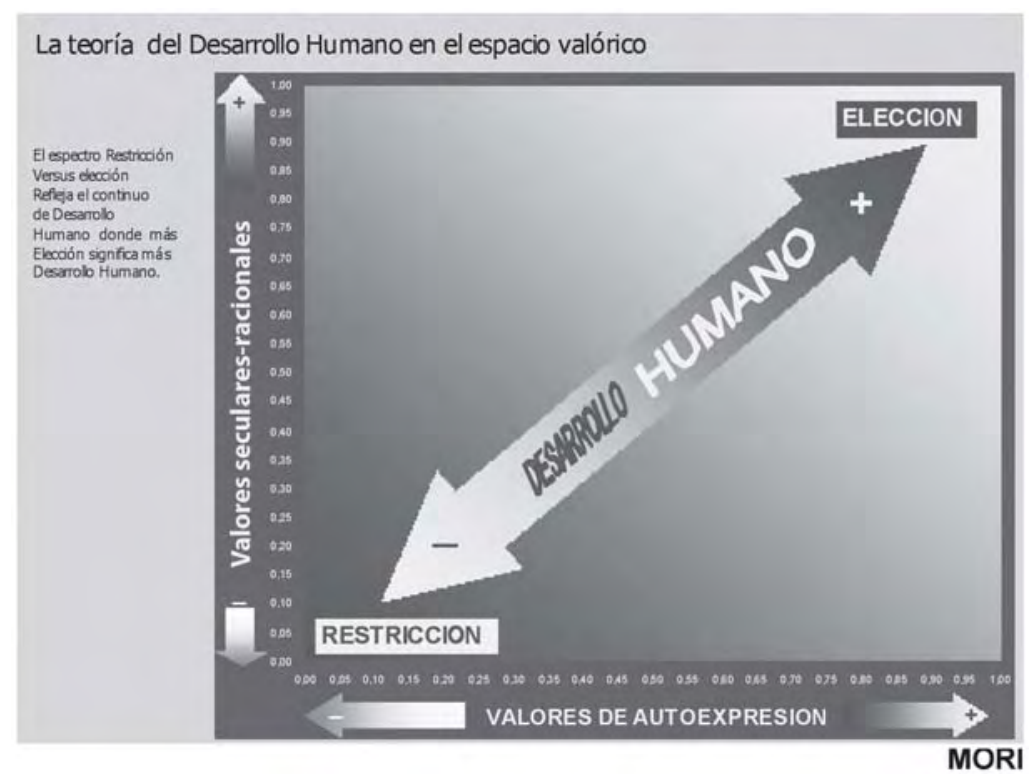


Revista de Sociología 21 / 2007 Chile Hoy

Facultad de Ciencias Sociales - Universidad de Chile

\section{Supervivencia / Autoexpresión}

En el eje de la supervivencia/auto-expresión se encuentran mayores grados de auto expresión cuando se enfatiza la libertad cívica y política, se usa y apoya la expresión pública, se tolera la no conformidad, se siente una dirección propia en la vida y se intuye confianza humana. Este tipo de actores tienen mayores grados de elección, mayor individualismo. El individualismo es el resultado de este proceso de cambio entre los valores de la supervivencia y los valores de auto-expresión, que las sociedades latinoamericanas están sufriendo fuertemente.

Marx se equivocó en casi todo, menos en predecir que el desarrollo económico trae cambios inevitables que transforman las sociedades mas allá de su voluntad. Es así como éste afecta tanto a China como a América Latina de la misma manera y sin consideración de sus valores o sistemas políticos instalados. Quizás el paralelo entre China y América Latina es que se prueba la fortaleza de las culturas existentes, resistentes al cambio valórico a pesar de éstos cambios inevitables producidos por el desarrollo econòmico. El mundo, lejos de converger hacia una manera de hacer las cosas, tiende a confirmar la diversidad, y la globalización no es otra cosa que el reconocimiento de esas diferencias.

En el eje de la supervivencia, el mundo aumenta su ingreso per capita de manera acelerada en los últimos 20 años, especialmente en los países emergentes, con la excepción de América Latina que pierde crecimiento, para recién recuperar los niveles de los años 80 en el año $2007^{3}$. Los valores cambian en este eje a distintas velocidades según el país y la zona geografica en la que se encuentra.

\section{Tradicionalismo / Secularización-Racionalidad.}

En el eje Tradicionalismo versus Secularización-Racionalidad se enfatiza el tradicionalismo cuando se remarca la religión, el patriotismo, se enseña la obediencia, y se apoya el familismo tradicional.

CEPAL, Informe Económico 2007.

En Chile se empezó a medir en 1990. 


\section{Una polaridad entre la Elección y la Restricción}
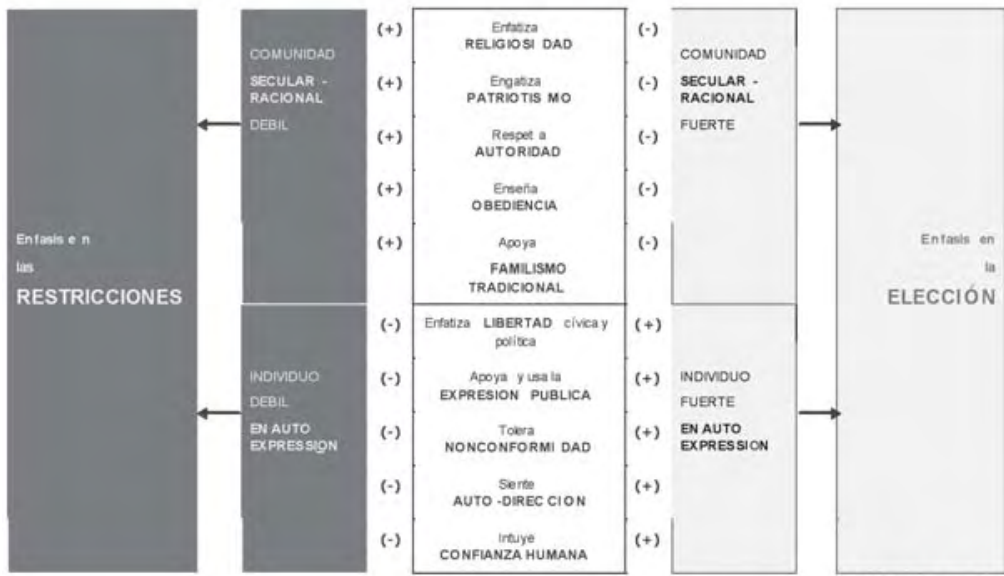

Fuente: ESTUDOO MUNDLAL DE VALORES MORL JUlio $2006 \mathrm{~N}=1000$

\section{MORI}

Las sociedades latinoamericanas cambian sus valores principalmente reforzando los valores tradicionales, en vez de ir hacia mayores niveles de racionalidad. Así las sociedades medidas entre 1980 y $2006^{4}$ se han desplazado desde la restricción a la elección, con la excepción de América Latina que se ha desplazado principalmente en el eje de la supervivencia- auto expresión, con la excepción de Chile.

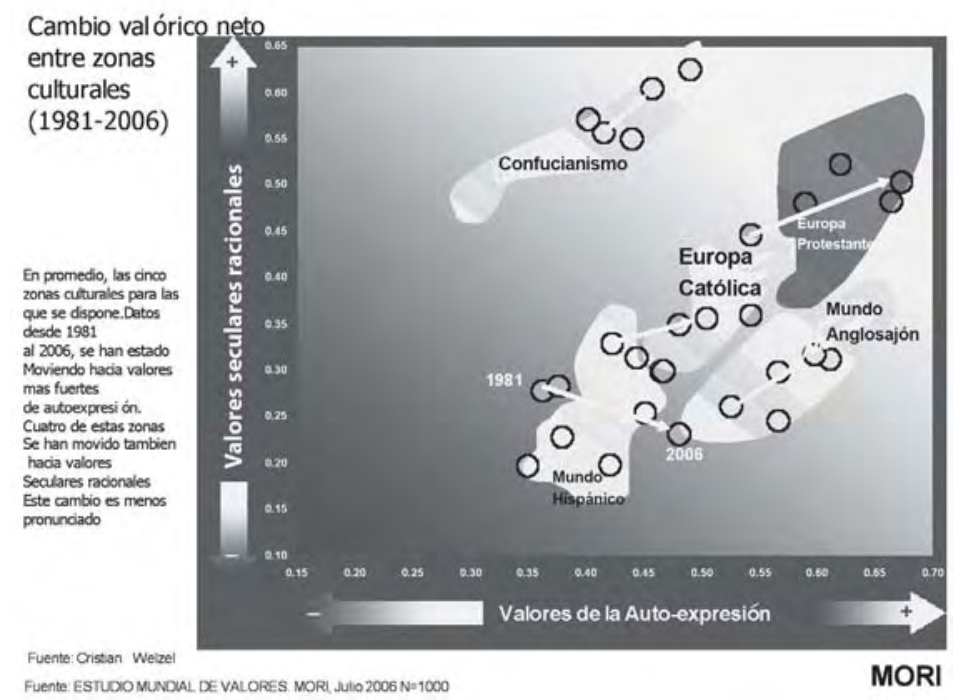

El aumento de la auto-expresión, del individualismo, como resultado de la prosperidad, tiene consecuencias inesperadas. En efecto, hasta el poder político parece perder 
atractivo ante el aumento del poder individual, (no sólo, ni en primer lugar, debido al poder que entrega el dinero) de la autodeterminación.

La incorporación de la India y la China al fuerte desarrollo económico en el oriente, al mismo tiempo que la globalización pone a prueba la relación entre la prosperidad y los valores tradicionales. De acuerdo a ello no seria necesario abandonar los valores tradicionales para llegar a la modernidad. Se trataría de una modernidad no secular. En estos cinco últimos años en que América Latina crece y recupera la situación que tenía el año 1980, no por ello cambia su rumbo de desarrollo valórico. Aumenta la prosperidad, se moderniza sin necesariamente secularizarse acorde como lo han hecho las sociedades del primer mundo.

\section{LA PROSPERIDAD Y LOS VALORES TRADICIONALES}

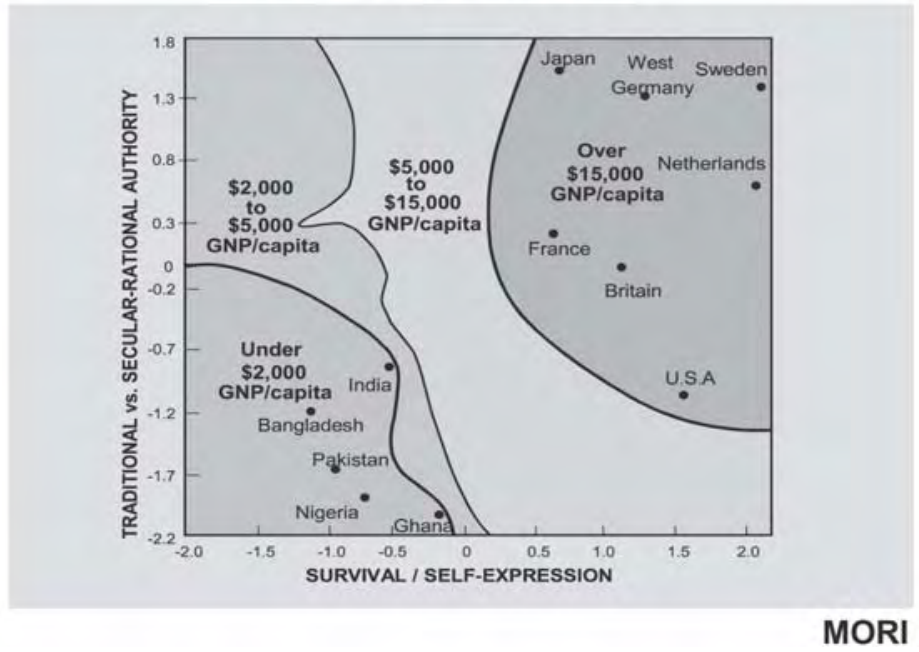

En un principio se creyó que después del materialismo (cambio valórico que acompaña la primera ola de crecimiento económico en las sociedades cuando éstas se aperan de bienes de consumo) vendría el posmaterialismo (cuando las sociedades ya provistas de bienes comienzan a preocuparse de los intangibles del desarrollo) $)^{5}$. Así es como a finales de la década del 70 comienzan a surgir los movimientos ecologistas, en plena prosperidad de la post guerra que le había dado al mundo occidental el período mas largo y mas próspero del siglo XX. Se modifican los sistemas de partidos, nacen los partidos verdes y surgen un nuevo referente de izquierda, que modifica el panorama político hasta la caída del muro de Berlín en 1990. En Europa el fin de la guerra fría simboliza el avenimiento de una socialdemocracia que comienza a empoderarse de las banderas de la globalización y la expansión de la democracia en el

Ronadl Inglehart 
mundo. El posmaterialismo muy visible en las pocas sociedades más ricas de la tierra se diluye en la expansión de la democracia. Fue muy breve el periodo de prosperidad sin globalización que gozaron los paises mas ricos de la tierra. La democracia al expandirse trajo consigo la globalización de la lucha contra la pobreza y la exclusión social. Los recientes acuerdos para sacar al África de la pobreza, así lo demuestran. La cohesión social como meta de ayuda al desarrollo marca una nueva era de los términos de la globalización. En ella la izquierda parece llevar la ventaja de marcar el signo de este tiempo presente en su lucha por la igualdad de los pueblos y de las personas en cada sociedad. El signo de los tiempos son las viejas banderas de la izquierda en el sentido de la igualdad. La democracia por su parte simboliza la lucha por la libertad, como su principal bandera y significado. ${ }^{6}$

Las banderas de la igualdad de la izquierda, las banderas de la libertad de la democracia, así como el sistema económico de economía de mercado, son las tres dimensiones valóricas que dominan las agendas de las sociedades en el momento de la realización de esta cuarta ola de medición del Estudio Mundial de Valores. Un mundo ecléctico, que no hay que intentar evaluarlo con las viejas coordenadas.

¿Cuáles son entonces las consecuencias de este proceso en América Latina?

Como dice Regis Debray, "Dios esta petrificado de cultura" y la creencia en él permea las costumbres, los hábitos, la manera de hacer las cosas. El hombre latinoamericano vive así una tensión entre los sustitutos racionales -que fundamentan su autodeterminación e individualismo- y las creencias. De algún modo, transita entre la modernidad y el tradicionalismo, entre el progreso y las costumbres.

Los hábitos se oponen a la modernidad, porque esta requiere quebrarlos para imponer su fría racionalidad. América Latina no cambia de hábitos, no moldea sus costumbres al son de una manera distinta de hacer las cosas. Combina así los hábitos, las costumbres, con una secularización limitada. Acepta el individualismo y aquellas cosas luminosas de la modernidad como la auto-expresión, pero rechaza la racionalidad que ella conlleva. Al mismo tiempo acepta los sustitutos de la racionalidad como son la tecnocracia que sustituye la política. Cuántas veces no he oído en estos 20 años, “¿Cuál es la tabla que dice eso?” como argumento para fundamentar una opinión. La técnica, que sustituye el ojo clínico en la medicina; el profesor, que sustituye la prosa por la respuesta múltiple; las maquinas calculadoras que hacen de la población analfabetos aritméticos; constituyen todos ejemplos formas sustitutivas de la racionalidad, que no fuerzan a cambiar las costumbres. Que el lector no se engañe, no hay tabla que compruebe cada frase.

Globalbarometro: www.globalbarometro.org 
El hombre latinoamericano se dispersa en esa tensión entre el pasado y el futuro, donde el futuro esta lleno de amenazas y el pasado lleno de certezas. Mientras el pasado tiene la certeza de la pertenencia, el futuro tiene la incertidumbre de la libertad. La libertad de decidir, de no tener autoridad a la cual "tener" que obedecer. La autoridad jerárquica permanece en este proceso de secularización limitada, manteniendo el orden establecido y restringiendo el proceso de democratización en la medida que no dispersa el poder, sino más bien consolida el poder jerárquico. El proceso de cambio de las sociedades latinoamericanas, que pueden llevar a mayores grados de democratización, implica el desmantelamiento de esa autoridad tradicional, donde la obediencia tiene un peso importante. Ese proceso ha sido lento y con altos niveles de resistencia al cambio, no solo en Chile sino en la gran parte de Amèrica Latina.

\section{Chile}

Chile aumenta los grados de libertad económica con el aumento de ingreso y de libertades cívicas y políticas derivadas del retorno a la democracia. Sin embargo hay una democratización limitada, que se manifiesta en el hecho de que las garantías cívicas y políticas no evolucionan hacia mayores grados de participación y no aumenta el grado de las garantías sociales y económicas colectivas a proporciones mayoritarias de la población. El aumento del ingreso proporciona beneficios personales a cada cual, sin que se traduzca en beneficios colectivos equivalentes. La sociedad no ve transformaciones de la estructura debido a la prosperidad. Esta prosperidad individual y no democrática consolida la desconfianza. El ciudadano puede acceder a bienes políticos y económicos limitados, pero no logra salir del cascarón en que nació, sino por el cambio intergeneracional, es decir a través de los hijos.

\section{Movilidad social:}

Dos de cada diez jóvenes de hogares donde ninguno de los padres ha tenido enseñanza superior, hoy día entran a un establecimiento de educación superior. Todavía 8 de cada diez jóvenes que terminan la educación media no siguen estudios superiores. La capacidad de movilidad social intergeneracional es limitada y si bien ha aumentado en estas últimas dos décadas, está lejos de satisfacer las expectativas de la población. Siete de cada diez jóvenes ${ }^{8}$ quieren entrar a la Educación Superior, pero sólo dos de cada diez lo logran. Se avanza a pasos lentos. ${ }^{9}$ En total en las ultimas cuatro generaciones, no ha aumentado la velocidad de la movilidad social de la manera

\footnotetext{
$7 \quad$ Siete de cada diez jóvenes que entran a la educación superior es la primera generación que la alcanza. En Chile cerca de 3 de cada diez jóvenes en total entran a algún establecimiento de educación superior.

8 Barómetro de la Educación Superior 2007 MORI.

9 En la formación de elites el país tiene una política restringida, con escasas becas de montos poco realistas para la formación integral de las generaciones de relevo, que tiende mas bien a reforzar una clase privilegiada" mucho mas que a la formación de una elite meritocrática. (Ejemplo: Becas Presidente de la Republica, insuficientes en monto cobertura y cantidad.)
} 
esperada. Aproximadamente $3^{10}$ de cada diez chilenos han tenido movilidad social de una generación a otra en la ultima década, hoy día esa cifra aumenta a cerca de cuatro chilenos de cada diez.

Todo lo anterior no contradice la afirmación oficialista de que hoy en el año 2008 siete de cada diez alumnos de la educación superior vienen de hogares donde no hay educación superior. Para ello basta recordar que Chile tiene solo un 20\% de educación universitaria y aumenta aproximadamente un año en promedio cada diez años. Si hoy tenemos 10 años de educación en promedio, en 20 años mas tendremos un promedio de 12 años, y en unos 50 años mas, si nos mantenemos a la misma velocidad, tendremos un promedio de educación universitaria equivalente a un pais desarrollado.

\section{El rol de la autoridad:}

La modernización del Estado no ha significado un empoderamiento del ciudadano, sino más bien ha reforzado su condición de súbdito, donde el Estado entrega y el ciudadano recibe. El aumento de su eficiencia no ha implicado que sea el ciudadano quien porta la soberanía. La capacidad de reclamo ha aumentado tímidamente, sin haber podido romper el hábito de que es mejor callar para no quedar mal. Es muy dificil hacerse oír para reclamar. Si bien se han abierto libros de reclamos, ¿cuantos de ellos tienen consecuencia o respuesta? Somos una sociedad sumisa a la autoridad aún, sin que nos atrevamos a levantar la voz en la defensa de nuestros derechos, aunque esto ha aumentado también. La voz es eufemística, indirecta, oblicua y se expresa cuando el costo es bajo o por canales anónimos, por ello los reality shows han tenido el impacto que tuvieron, o las fotos de miles de chilenos desnudos en el anonimato. Permiten la expresión anónima de los silencios reprimidos, de la diversidad inexpresada. Preferimos complacer el hábito dominante a romper lo establecido defendiendo nuestros derechos.

El aumento de grados de igualdad se restringe a aquellos elementos que no requieren el cambio de la estructura de la sociedad. El aumento de grados de libertad, tanto de expresión como cívica, se limita a aquellos aspectos que no afectan el orden establecido. El acceso a bienes políticos no implica dispersión del poder. Es más, se limita a aquellos bienes que no requieren dispersión del poder.

En ese sentido el mayor "error" del gobierno de Michelle Bachelet es haber roto ese empate silencioso, habiendo explicitado lo que nos incomoda. La tensión entre tra-

10 Latinbarometro serie 1995 2007- La movilidad social aumenta de 27\% en el 2000 a 36\% en el 2006. La movilidad social medida en base a la comparación de la educación de los hijos con los padres. Tiene movilidad social el hijo que alcanza un grado distinto de educación que el padre; de educación basica a media, de media a educación superior, de basica a educación superior. 
bajadores y empresarios es el secreto a voces mejor guardado de la sociedad chilena, que ha salido del baúl. En una cultura fuertemente dominada por las costumbres, es incorrecto forzar crisis o producir conflictos para solucionar temas de larga data. Es así como los sobresueldos solo se solucionan cuando no queda otro camino porque explota una crisis, no porque alguien haya decidido enfrentarlo. La lista es larga de los homólogos de los sobresueldos, donde la política o la sociedad deciden no abordarlos, porque prefiere el estatus quo

Un ejemplo de la evolución valòrica de los chilenos en el tema de la autoridad es el peso de la obediencia. Esta en vez de disminuir en importancia para enseñar, aumenta de $46 \%$ a 52\% entre el 1990 y 2006 . Refuerza los valores tradicionales en vez de desmantelarlos.

\section{ENSEÑAR A LOS NIÑOS...}

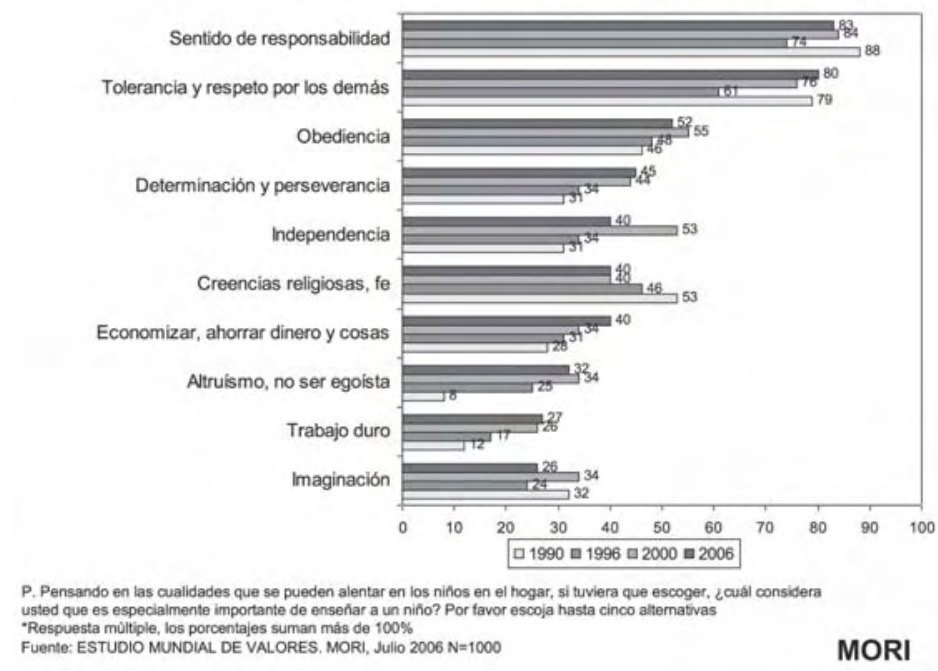

Por otra parte, el haber explicitado silencios incomodos tendra consecuencias duraderas con importante impacto en las actitudes. En otras palabras, para hacer tortillas hay que quebrar huevos. No es posible transformar una sociedad sin producir quiebres. Los elemenos de posibles de cambiar via reforma son limitados.

\section{La pluralidad limitada}

Por lo anterior, hay una pluralidad limitada, una tolerancia relativa de la diversidad y mucha resistencia a la objetividad sin apellidos. El peso de la obediencia fuerza a lo políticamente correcto. La bruta realidad no tiene expresión verbal, el 70\% de la gente no dice lo que piensa. El acceso al poder de la información está aún limitada, los grados de competencia son limitados, hay monopolios, pocos bienes públicos a disposición del publico en general. 
El control social y político de la agenda es total. Se trata de una sociedad controlada por el poder de pocos, sin la clara expresión de las minorías, ausentes, con pocos y a veces con ningún canal de expresión. Somos un rebaño que no disiente sino con el silencio. Los dos millones no inscritos en los registros electorales es una evidencia de ese fenómeno.

El siguiente perfil de bienes puede dar una idea de la dispersión/concentración del poder. Un 12\% tiene cuenta bancaria, un 29\% tiene tarjeta de crédito de algún tipo, mientras el 76\% tiene celular, un 95\% tiene una comida al día y televisión el 98\%. ${ }^{11}$ Cuando se afirma que Chile ha cambiado, es porque efectivamente hay cosas que han cambiado. Hoy 76\% dice tener celular, pero se omite la mención de que el acceso al crédito y al sistema bancario en general todavía no se masifica. Esto ejemplifica como el cambio es restringido a elementos que no entregan empoderamiento de los ciudadanos para competir en una sociedad abierta. Mientras la televisión globaliza las demandas, la estructura de la sociedad no entrega canales para su satisfacción.

\section{La prosperidad}

La prosperidad aumenta sin importar los grados de democratización. La prosperidad es ciertamente no democrática, por lo que parece obvio que la China será primero rica y luego quizás, democrática. Los datos Latinobarómetro $2007^{12}$ muestran cómo el crecimiento económico no produce más democracia, sino más demanda por ella, en la medida que se constata el aumento de la brecha entre los ricos y los pobres.

Pero el aumento de la brecha no es sólo al interior de los países, sino entre los países. Nos encontramos hoy entonces con dos mundos mucho mas aparte que lo que estaba el mundo en los años 80. Nosotros en América Latina vivimos en ese mundo donde los millonarios no son multitud. Pertenecemos a aquella categoría de países equivalente a una clase social media, aspiracional, ascendente, pero todavía con dificultades para pagar los bienes de lujo sin crédito. Basta con ello mirar nuestro candidato presidencial, un millonario para nuestros estándares, que sin embargo se ha comprado un helicóptero a medias con otro empresario. Eso nos dimensiona nuestra prosperidad.

¿Cómo han evolucionado los valores en este contexto? ¿Dónde se mezcla lo antiguo con lo nuevo, lo tradicional y lo moderno?

11 Latinobarómetro 1995 -2007

12 Informe Latinobarómetro 2007 www.latinobarometro.org 
ReVista de Sociología 21 / 2007 Chile Hoy

Facultad de Ciencias Sociales - Universidad de Chile

\section{La secularización}

El proceso de secularización en Chile es muy lento a pesar que los analistas desde 1987 que intentan comprobar cuánto ha disminuido el catolicismo y aumentado el protestantismo y el ateísmo. En 1987 desde Flacso Chile se intentó demostrar el gran paso a la secularización que había dado Chile, en un momento donde los comunistas rezaban el ""padre nuestro" en la catedral, aplaudiendo a la Iglesia Católica por su defensa de la vida frente a la dictadura.Veinte años después, los que se declaran católicos ha disminuido impresionantemente poco de un 79\% en el año 2006 a un 69\% en ${ }^{13} \mathrm{el}$ año 2007, si bien ha disminuido mucho mas la práctica religiosa.

La importancia de Dios en la vida no cambia en el período entre 1990 y 2006.

\section{IMPORTANCIA DE DIOS EN SU VIDA}

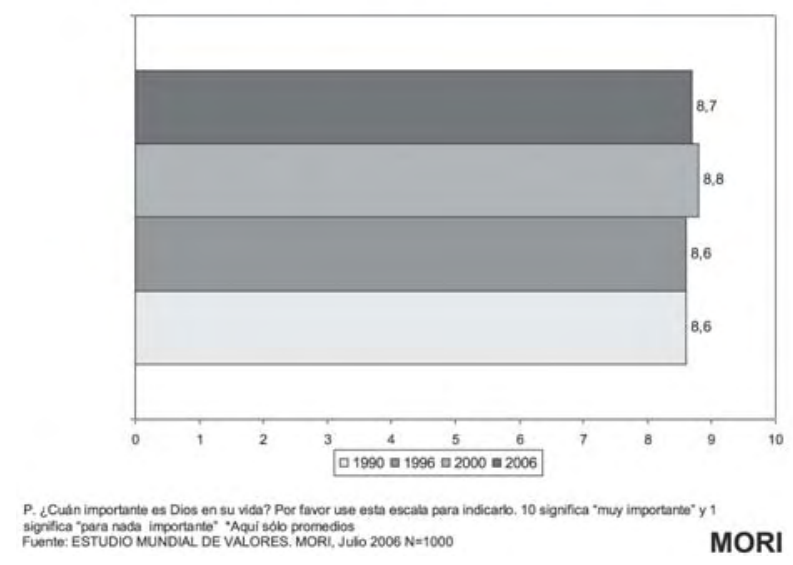

Lo que cambia lentamente es la oración que diminuye de $85 \%$ a $77 \%$ en el mismo período así como la autodefinición de religiosidad que disminuye de 77\% a 63\%.

\section{¿TIENE UD. MOMENTOS DE ORACIÓN, REZO, MEDITACIÓN, CONTEMPLACIÓN?}

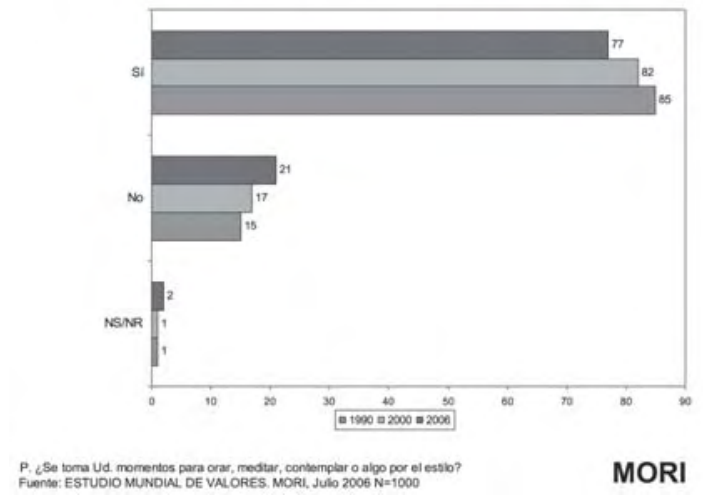

3 Latinobarómetro 


\section{¿ES UD. UNA PERSONA RELIGIOSA?}

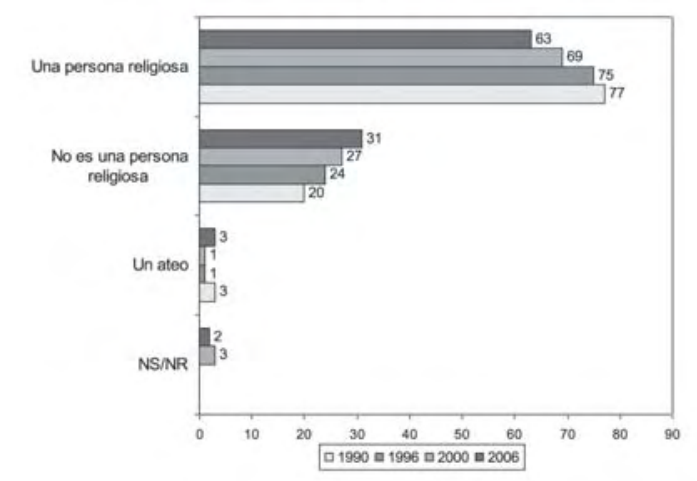

Aumenta la tolerancia hacia el suicidio, aborto, prostitución, eutanasia, homosexualidad y divorcio, entre 1990 y 2006 sin excepción. Los grados de aumento sin embargo son escasos para el suicidio, el aborto y la eutanasia, mientras se duplica la tolerancia a la prostitución. Lo que cambia más rápidamente es la tolerancia hacia la homosexualidad, que aumenta de 1.8 a 4.6 entre 1990 y 2006. Mientras el divorcio aumenta de 3.5 a 6 en el mismo período. No se puede decir a la luz de estos datos que Chile ha tenido un destape valórico, como lo tuvo España después de la muerte de Franco.

\section{GRADO DE JUSTIFICACIÓN DEL...}

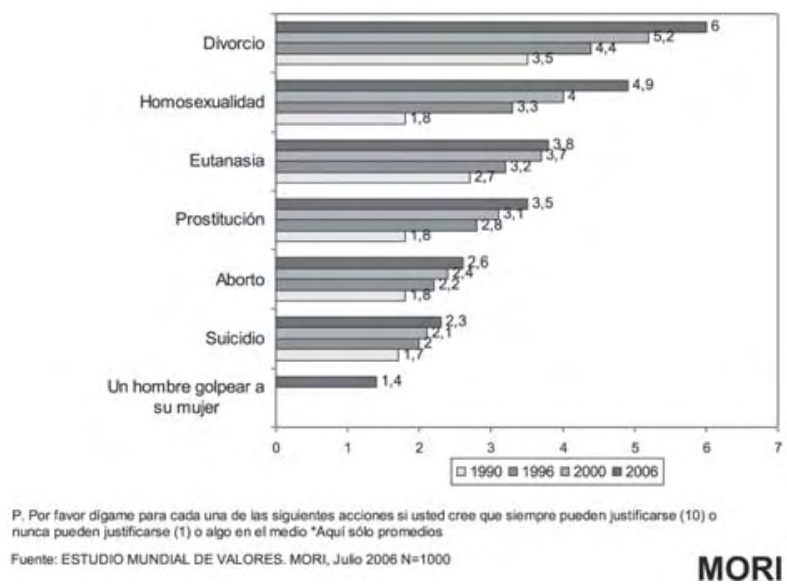

En el tema del matrimonio, asunto que está de manera permanente en la agenda valórica, vemos que el aumento del apoyo al divorcio no ha significado una disminución correspondiente de la validez del matrimonio. Este disminuye de 84\% a 69\% en el mismo período. 
ReVista de Sociolocía 21 / 2007 ChILe Hoy

Facultad de Ciencias Sociales - Universidad de Chile

\section{EL MATRIMONIO ES UNA INSTITUCIÓN ANTICUADA}

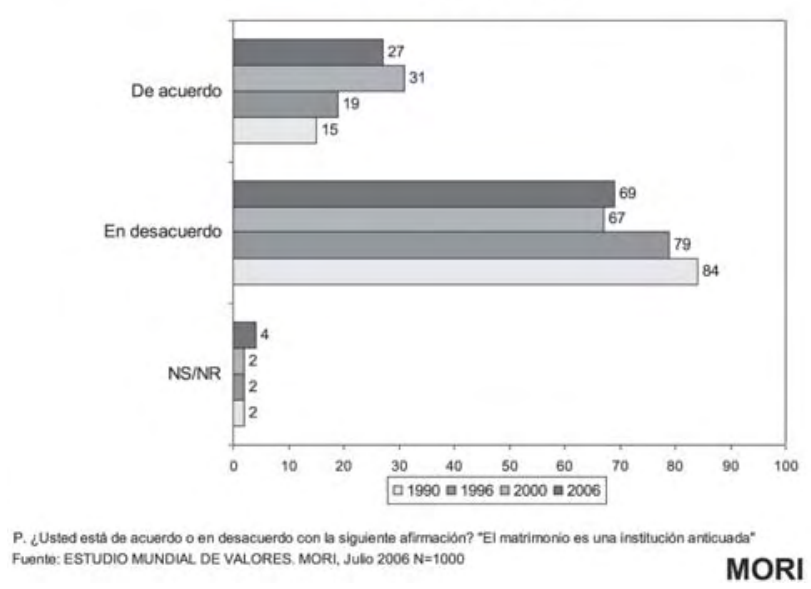

De un consenso total respecto del contenido del concepto de familia de $92 \%$ en el año 1990, se disminuye a 75\% en el 2006.

\section{UN NIÑO NECESITA DE UN HOGAR CON AMBOS PADRES}

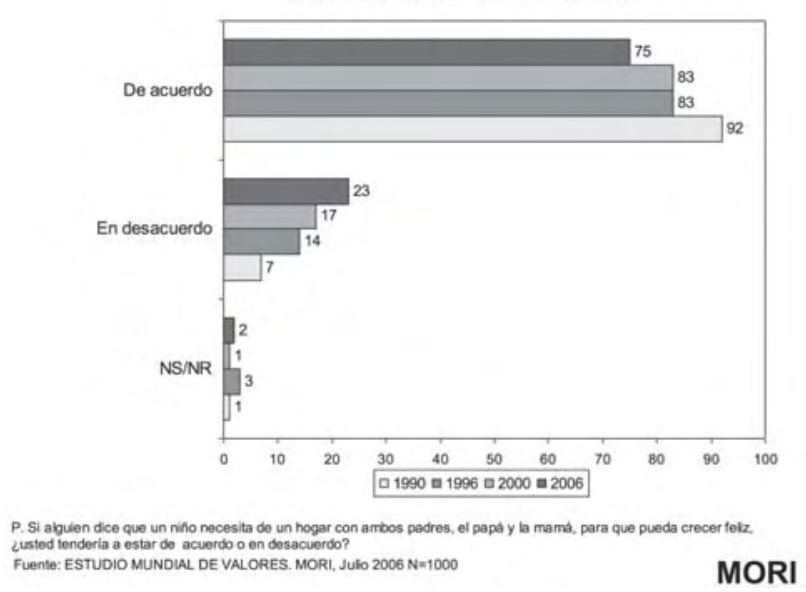

Chile -entre 1990 y 2006- pasa de ser una sociedad donde había consenso de sociedad tradicional a ser una sociedad tradicional en el inicio del proceso de cambio. Ese es el mayor cambio que ha sufrido Chile en este período: el haber perdido los consensos de la sociedad tradicional.

Si en 16 años esos son los cambios valóricos que ha tenido Chile, entonces podemos decir que para alcanzar los valores que tiene el promedio de las sociedades europeas más prósperas, en esas mismas variables, se necesitan unos 30 a 40 años. En otras palabras queda claro que esos valores de esa modernidad no son populares en la so- 
ciedad chilena de hoy, especialmente ante la alarma pública que denuncia el excesivo cambio que ha tenido la sociedad chilena en estos tiempos.

La lentitud del cambio valórico que ejemplificamos con estos datos es la primera característica de la sociedad chilena, aunque los chilenos declaren lo contrario, y crean que éste ha sido vertiginoso. Definitivamente esto no es así si se toma la referencia de la velocidad de los cambios de otras sociedades. Tampoco es así respecto de la velocidad de cambio de la propia sociedad chilena en el pasado, como lo muestra la comparación con los escritos del Padre Hurtado, ${ }^{14}$

"recrudecimiento de la moral pagana, del materialismo agnóstico, junto al pesimismo que ha pesado sobre el mundo esos últimos 20 años, han sido los grandes responsables de la pérdida gradual de las costumbres." "El ideal pagano, materialista, vivificado por una filosofía pragmática, relativista, se ha apoderado de la masa de los ciudadanos”.

En el pasado Chile cambiaba también a velocidades que parecían vertiginosas, como lo describe el Padre Hurtado, de tal manera que no se podría desde ese punto de vista señalar el tiempo presente como un tiempo de cambios extraordinarios, sino más bien de una evolución conocida.

Si los chilenos dicen que todo cambia muy rápido es porque no les gusta el cambio y más bien le temen a él. Los chilenos en general son bastante adversos al riesgo, quieren más bien preservar la manera como se hacen las cosas y no cambiarlas. Para ellos el cambio es una suerte de amenaza más que una oportunidad. Esto puede parecer contradictorio con la capacidad emprendedora y la fama de los ejecutivos chilenos como buenos empresarios, pero no lo es. Incluso más, es posible que ésta sea una razón de su éxito: la tendencia a los cambios lentos y seguros. El tener un grupo de empresarios exitosos no está relacionado con la demanda y proceso de transformación que se espera de la sociedad chilena.

La lista de cosas que no han cambiado en 20 años es enorme. La innovación en materias centrales de la sociedad es escasa. Estamos en una etapa en que copiamos lo que hacen otros, nuestra imaginación no ha cambiado en importancia como valor desde 1990.

\section{El tiempo libre}

No aumenta estructuralmente la disponibilidad de tiempo libre. El pueblo chileno tiene hoy la misma cantidad y dispersión de vacaciones que tenía hace 20 años atrás. Una de las cosas que más cambia en las sociedades modernas, a medida que se hacen 
mas prósperas, es la cantidad de tiempo libre que cada cual dispone. Los chilenos están forzados a tomar sus vacaciones en el verano principalmente y carecen de interrupciones cortas para descansar a lo largo del año. Ello origina todo tipo de males sociales, como el ausentismo laboral de los Lunes, los fines de semana sándwich no declarados como vacaciones, el abuso de licencias médicas para otros fines, la solicitud de licencias siquiátricas por exceso de stress, entre otras manifestaciones. Lo que sí aumenta es la cantidad de tiempo libre que tiene cada cual en la medida que aumenta su ingreso, lo que expresa un desarrollo individualista, no colectivo. Es decir cada cual goza de su tiempo libre sin que la sociedad como tal asuma un cambio de manera de mirar como colectivamente se goza el tiempo libre. Un ejemplo claro del individualismo característico de nuestro desarrollo. Es paradojal que las sociedades menos religiosas paren una o dos semanas para Navidad y el mundo latinoamericano católico no tenga pausas oficialmente declaradas. Mientras las sociedades más ricas tienen 50 días de vacaciones al año, nosotros tenemos 15 días oficiales. ¿Alguien ha sacado la cuenta cuantos días de vacaciones reales tienen los trabajadores chilenos, contados las licencias ficticias, los ausentismos, los sándwich no declarados?

Se requiere con urgencia sincerar la disponibilidad de tiempo libre quenecesita una sociedad y blanquear los privilegios ocultos de algunos y los abusos de otros para que cambie la estructura de la disponibilidad de tiempo libre que tiene la sociedad chilena. El tiempo libre mínimo es una condición para el equilibrio de la sociedad, que aquí esta fuertemente estratificado. La ausencia de un sindicalismo fuerte ha llevado a esta situación que ahora perjudica el ánimo de la nación, en la medida que afecta el rendimiento promedio de la sociedad..

En Chile aumenta la importancia del tiempo libre de 33\% a 47\% entre 1990 y 2006, a los niveles que tienen países desarrollados. Pero IMPORTANCIA DEL TIEMPO LIBRE esta importancia no se refleja en cambios producidos en la estructura de la sociedad o en su normativa. Esto origina una tensión evidente entre la demanda creciente de tiempo libre y el tiempo asignado por norma o por costumbre. La insatisfacción sobre el tiempo libre que sufre como consecuencia la sociedad

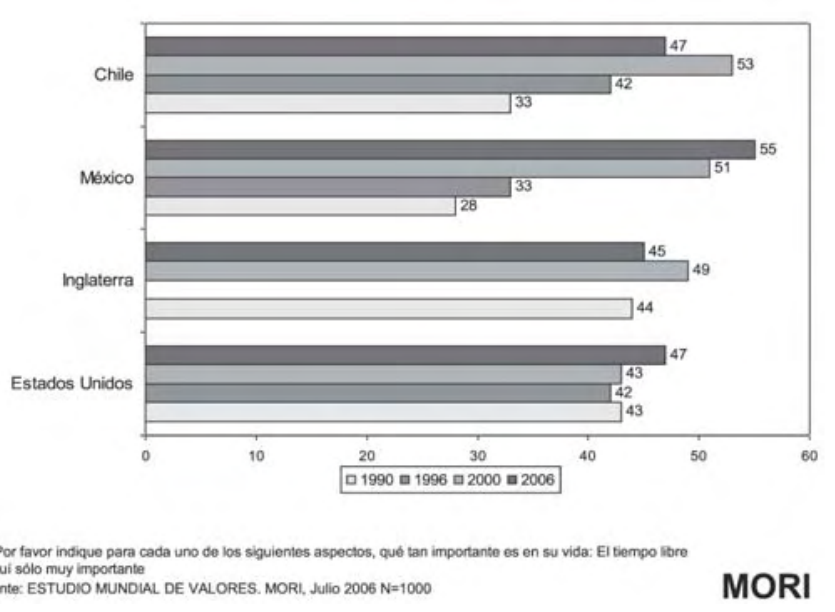


chilena es un aspecto que todavía queda por revelar, que no ha sido objeto de la agenda, ni de política publica, ni siquiera de temas de teleseries.

\section{La mentalidad económica}

Ha sorprendido en toda America Latina los resultados de Latinobarómetro 2007 donde después de 5 años de crecimiento económico, el mayor impacto se ve en un aumento del rechazo a la economía de mercado.

La mentalidad económica no se consolida hacia la aceptación de la competencia como motor del desarrollo, aumentando de 4.1 a 4.9 la percepción de que la competencia es dañina. ¿Como puede ser de otro modo en una sociedad donde una minoría tiene acceso al "mercado", entendido como el acceso al crédito, al consumo, a los bienes masivos? Con un ingreso promedio de $\$ 300.000$, ¿cuánto acceso al mercado se puede tener? No se ha señalado con suficiente fuerza la importancia del rol democratizador que han tenido las tarjetas de las casas comerciales, que le han entregado acceso al "mercado" a una parte excluida de la sociedad. No es razonable pensar que habrá aceptación de la economia de mercado sin que haya participación de ésta.

\section{LA COMPETENCIA}

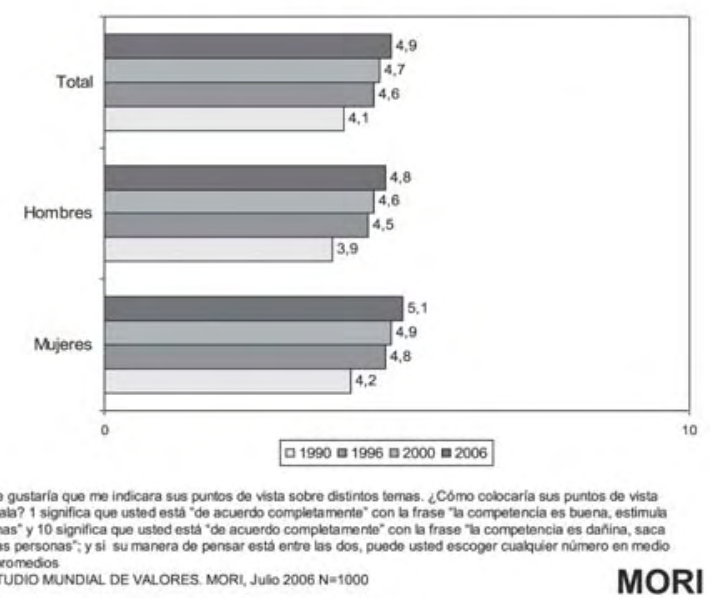

En una sociedad donde la prosperidad no es democrática y el mercado funciona de manera limitada para muchos, no hay que esperar que sus valores se consoliden.

\section{La interacción}

Tampoco hemos cambiado nuestra manera de interactuar, seguimos atados por las desconfianzas, certificando nuestras existencias hasta el absurdo. Ante la sospecha de abuso, más vale impedir la racionalidad y la eficiencia, siendo mejor certificar, paralizar, entrampar. 
Revista de Sociología $21 / 2007$ Chile Hoy

Facultad de Ciencias Sociales - Universidad de Chile

El Estado es el primer culpable de esta gran desconfianza, que pide certificación de la certificación. ¿En que consiste un estado fuerte? ¿En la cantidad de certificaciones o en su capacidad de imponer la ley y hacer efectivas las sanciones?

La desconfianza normativa que embarga nuestras leyes se basa en el hecho real de que efectivamente tenemos una población que intenta sacar partido de las cosas. A menor educación, mayor proporción de la población que intenta sacar partido de una situación. En general el pueblo chileno intenta más bien sacar partido de las cosas que ser justo, de acuerdo a estos resultados 2007 de Latinobarómetro.TABLA 1 Pero es un círculo vicioso porque lo que se intenta es compensar las discriminaciones y desigualdades estructurales evidentes.

Entonces el fraude social que se produce con el no pago del boleto del bus, o uso indebido de licencia, es ."'legítimo y justificable" aunque en teoría "moralmente condenable". En otras palabras, no es correcto, pero en este caso si.

Tabla Nº : Promedio escala trataría de sacar partido (0) v/s trataría de ser justo (10), según educación (medias)

\begin{tabular}{|c|c|c|c|}
\hline \multicolumn{3}{|c|}{ Educación } & \multirow{2}{*}{ Total } \\
\hline Básica y menos & Media y menos & Superior y menos & 3,8 \\
\hline 3,4 & 3,9 & 4,1 & 3 \\
\hline
\end{tabular}

Fuente: Latinobarómetro 2007. Datos Chile.

La evolución de los valores no ha roto la brecha de la desconfianza. En 20 años no hemos reducido, sino consolidado la desconfianza. Hemos cerrado las redes de confianza en vez de abrirlas. En esto es donde más nos diferenciamos de las sociedades del primer mundo y donde parece que queremos cambiar.

\section{CONFIANZA INTERPERSONAL}

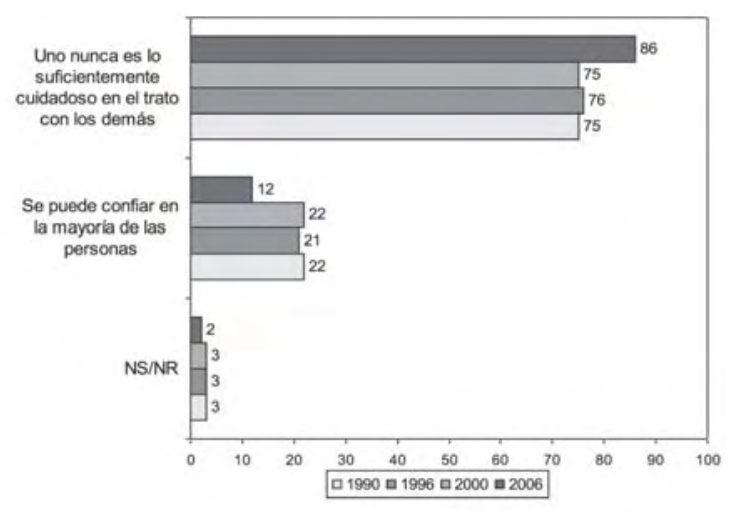


Tabla N²: Confianza interpersonal, según sexo, edad y educación (Porcentajes)

\begin{tabular}{|c|c|c|c|c|c|c|c|c|c|c|}
\hline & \multicolumn{2}{|c|}{ Sexo } & \multicolumn{4}{|c|}{ Edad } & \multicolumn{3}{|c|}{ Educación } & \multirow[b]{2}{*}{ Total } \\
\hline & Hombre & Mujer & $\begin{array}{r}18- \\
25 \\
\text { años } \\
\end{array}$ & $\begin{array}{c}26- \\
40 \\
\text { años } \\
\end{array}$ & $\begin{array}{c}41- \\
60 \\
\text { años } \\
\end{array}$ & $\begin{array}{l}61 \text { y } \\
\text { más } \\
\text { años }\end{array}$ & $\begin{array}{c}\text { Básica } \\
\text { y } \\
\text { menos } \\
\end{array}$ & $\begin{array}{c}\text { Media } \\
\text { y } \\
\text { menos }\end{array}$ & $\begin{array}{c}\text { Superior } \\
\text { y } \\
\text { menos }\end{array}$ & \\
\hline $\begin{array}{c}\text { Se puede } \\
\text { confiar en } \\
\text { la mayoría } \\
\text { de las } \\
\text { personas }\end{array}$ & 15 & 10 & 14 & 15 & 14 & 7 & 11 & 10 & 19 & 12 \\
\hline $\begin{array}{c}\text { Uno } \\
\text { nunca } \\
\text { es lo } \\
\text { suficiente- } \\
\text { mente } \\
\text { cuidadoso }\end{array}$ & 84 & 88 & 84 & 84 & 86 & 91 & 88 & 89 & 80 & 86 \\
\hline NS/NR & 1 & 2 & 2 & 1 & 0 & 2 & 1 & 1 & 1 & 2 \\
\hline
\end{tabular}

Fuente: World Values Survey 2006. Datos Chile.

La confianza hacia terceros desconocidos, medida con la variable de Ronald Inglehart "." confianza interpersonal", que ha dominado los estudios empíricos de confianza en la literatura de las ciencias sociales, ha disminuido en Chile en el período medido. El tipo de confianza que tenemos afecta la manera como enfrentamos el conflicto, la manera como miramos la autoridad, es lo que nos diferencia de otras sociedades en otras latitudes, como las asiáticas o las europeas.

La confianza en la sociedad chilena está basada en el conocimiento personal, en el contacto, en la experiencia, se constituye en redes. Al interior de las redes se confía en quienes aparecen como pares. Los más pobres confian en sus pares, los mas pobres. Los que tienen más educación confian menos en los pobres, con los cuales quizás interactúan menos, pero más en los vecinos que son más parecidos a ellos. En el extranjero se confia menos que en el vecino y el pobre. Una trama de confianzas que interpela. Se confia en quienes son mas parecidos a cada cual. ¿Cómo es la tolerancia consecuencia de esas confianzas?

Tabla N³: Confianza (\%)

\begin{tabular}{|c|c|c|c|c|}
\hline & \multicolumn{4}{|c|}{ Educación } \\
\cline { 2 - 5 } & Básica y menos & Media y menos & Superior y menos & 28 \\
\hline $\begin{array}{c}\text { Familiar que no } \\
\text { se conoce }\end{array}$ & 33 & 24 & 35 & 31 \\
\hline Extranjero & 33 & 28 & 59 & 54 \\
\hline Vecino & 55 & 51 & 57 & 56 \\
\hline Pobre & 63 & 51 & & 28 \\
\hline
\end{tabular}

„Aquí sólo "mucha confianza" y "algo de confianza"

Fuente: Latinobarómetro 2007. Datos Chile. 
Esto constituye redes de confianza en torno a grupos de personas. Los amigos, la gente en el trabajo, los vecinos, constituyen conjuntos de interacción entre los cuales reinan altos grados de confianza.Afuera de esos conjuntos hay grandes desconfianzas, especialmente hacia otros grupos y redes. Así los empresarios conocen y confian en los empresarios, los trabajadores con los trabajadores, pero no entre ellos. Por ello se perciben altos niveles de conflicto entre las redes que se desconfian. Los ricos de los pobres, los empresarios de los trabajadores.

No es de extrañar en esas circunstancias los estigmas que pesan sobre algunos grupos de la sociedad, por ejemplo los jóvenes. Basta que unos pocos jóvenes tengan actitudes poco loables para que la gente piense que en general los jóvenes se comportan así. La gente termina basando su actitud hacia los jóvenes, en este ejemplo,a la luz de su comportamiento colectivo, que se trasluce a través de los medios de comunicación.

El peso de las imágenes se produce por ese proceso, en el cual, en ausencia de experiencia e información concreta, se sustituye la experiencia directa por las actitudes y comportamientos que se ven en los medios, formándose opiniones en torno a ellas. Las opiniones no se configuran por lo que se sabe de ellas mas allá de las noticias, por la educación, la lectura, los análisis, sino más bien por el sustituto de experiencia que se deriva de las noticias. Los medios son así sustitutos de experiencia en base a los cuales se forman las actitudes y se basan los comportamientos. El peso de las imágenes es por ello preponderante, porque en la ausencia de confianzas abiertas a terceros, los sustitutos de experiencia de cualquier tipo entregan elementos para juzgar. Somos un país que vive de las imágenes, nos comunicamos con símbolos que los recibimos a la defensiva, con actitudes para protegernos de lo desconocido. Es el lado oscuro de la sociedad tradicional, donde la racionalidad secular no funciona desmantelando mitos, prejuicios y estereotipos, sino que estos se ven reforzados por las costumbres. Estamos entrampados en los estereotipos tradicionales sin poder abrir las compuertas de los hechos objetivos para entrar a una sociedad abierta.

En definitiva la interacción de los ciudadanos está filtrada por dos elementos. En primer lugar por el contacto directo que es la fuente de confianza entre las personas, y en segundo lugar por la información de los medios de comunicación que es la fuente más creíble de interacción después de la experiencia. Con esos dos componentes se construye la trama de confianzas, las imágenes y por ende las determinantes del comportamiento. La importancia de los medios de comunicación en sociedades como estas tiene mucho más peso que en sociedades con altos niveles de racionalidad donde los mitos, prejuicios y estereotipos se destruyen con la objetividad.

Por ello no debe extrañar que las confianzas de las instituciones de la sociedad y de la democracia sean tan escuetas, como ya se ha reporteado casi majaderamente en 
estas casi dos décadas. No puede haber mayores niveles de confianza en instituciones en la medida que las confianzas estén basadas en la experiencia e indirectamente a través de los medios.

Tabla No 4 : Confianza (\%)

\begin{tabular}{|c|c|}
\hline & Total \\
\hline Los bomberos & 86 \\
\hline La policía & 70 \\
\hline La iglesia & 69 \\
\hline Las radios & 65 \\
\hline Las fuerzas armadas & 62 \\
\hline El presidente & 54 \\
\hline Un chileno & 50 \\
\hline La televisión & 49 \\
\hline Los diarios & 48 \\
\hline Un indígena & 46 \\
\hline Gobierno & 45 \\
\hline El tribunal electoral & 41 \\
\hline La empresa privada & 37 \\
\hline El congreso nacional & 28 \\
\hline El poder judicial & 21 \\
\hline Los partidos políticos & 20 \\
\hline
\end{tabular}

En la medida que las sociedades son capaces de crear confianzas institucionales abstractas, en esa medida es posible encontrar altos niveles de confianza hacia ellas. Esta es una diferencia cultural básica que distingue a Chile y toda America Latina, fundamentalmente de otras regiones del mundo: Europa y Asia principalmente. Tiene por cierto que ver con la democracia, pero en primer lugar tiene que ver con esa cultura que no cambia.

Vale señalar que esa manera de construir confianza acentúa el individualismo, ya que fuerza a que las personas salgan del círculo primario en el cual interactúan con pares en los cuales confian, desconfien más allá de ellos. En el año 2002 MORI hizo un extenso estudio para la Dirección de Organizaciones Sociales del Estado, comprobando como 66\% de los chilenos participaban en algún tipo de organización, incluyendo las religiosas. Sin embargo, su involucramiento en organizaciones dedicadas a lo "colectivo." era extremadamente escaso. El chileno suele ser un gran voluntario, especialmente en situaciones extraordinarias, cuando hay una catástrofe de cualquier tipo, o para una acción solidaria (mayoritariamente de iglesia), pero no suele emprender acciones colectivas cívicas que involucran la creación de bienes públicos. Son más bien bienes individuales, para personas individuales, a través de la caridad, el voluntariado, el asistencialismo y muchas actividades de tipo parternalista. Los resultados del WVS muestran lo mismo. 
ReVista de Sociolocía 21 / 2007 ChILe Hoy

Facultad de Ciencias Sociales - Universidad de Chile

Distinto es el caso de las sociedades más modernas en que grupos de personas desconocidas unas de otras se juntan para defender una causa común, que es una causa de la sociedad, ya sea un derecho o una obligación, en la construcción del bien común. En sociedades donde reina la desconfianza con terceros, es casi imposible la construcción de bien común como meta societal.Y éste se convierte en una prueba de fuerza, contra la corriente. Esto resulta contradictorio al observar la demanda de la igualdad ante la ley que tiene como base un bien común mínimo.

El individualismo permea incluso la manera como se expresa esa solidaridad y participación, que pasan a ser asuntos de cada cual y no de la sociedad en su conjunto.

Tabla Nº5: Participación activa en organizaciones; según sexo, edad y educación (Porcentajes)

\begin{tabular}{|c|c|c|c|c|c|c|c|c|c|c|}
\hline & \multicolumn{2}{|c|}{ Sexo } & \multicolumn{4}{|c|}{ Edad } & \multicolumn{3}{|c|}{ Educación } & \multirow[b]{2}{*}{ Total } \\
\hline & Hombre & Mujer & $\begin{array}{c}18- \\
25 \\
\text { años }\end{array}$ & $\begin{array}{c}26-40 \\
\text { años }\end{array}$ & $\begin{array}{c}41- \\
60 \\
\text { años }\end{array}$ & $\begin{array}{l}61 \text { y } \\
\text { más } \\
\text { años }\end{array}$ & $\begin{array}{c}\text { Básica } \\
\text { y } \\
\text { menos }\end{array}$ & $\begin{array}{c}\text { Media } \\
y \\
\text { menos }\end{array}$ & $\begin{array}{l}\text { Superior } \\
\text { y menos }\end{array}$ & \\
\hline $\begin{array}{l}\text { Iglesia u } \\
\text { organización } \\
\text { religiosa }\end{array}$ & 16 & 30 & 18 & 19 & 21 & 33 & 25 & 23 & 19 & 23 \\
\hline O. deportiva & 19 & 8 & 21 & 17 & 13 & 6 & 10 & 16 & 15 & 13 \\
\hline O. educativa & 10 & 11 & 23 & 13 & 8 & 4 & 3 & 9 & 24 & 10 \\
\hline Sindicato & 5 & 2 & 3 & 5 & 5 & 2 & 2 & 5 & 5 & 4 \\
\hline $\begin{array}{l}\text { Partido } \\
\text { político }\end{array}$ & 2 & 2 & 2 & 2 & 2 & 1 & 0 & 3 & 2 & 2 \\
\hline O. ecologista & 2 & 1 & 2 & 2 & 1 & 2 & 1 & 1 & 3 & 2 \\
\hline $\begin{array}{c}\text { Asoc. } \\
\text { Profesional }\end{array}$ & 4 & 3 & 6 & 3 & 4 & 0 & 0 & 3 & 8 & 3 \\
\hline $\begin{array}{l}\text { O. humanitaria } \\
\text { o de caridad }\end{array}$ & 5 & 10 & 8 & 8 & 9 & 5 & 5 & 6 & 15 & 8 \\
\hline Otro & 1 & 3 & 1 & 1 & 2 & 2 & 3 & 1 & 1 & 2 \\
\hline
\end{tabular}

„Aquí sólo "miembro activo"

Fuente: World Values Survey 2006. Datos Chile.

\section{¿La restricción o la elección?}

Las sociedades latinoamericanas no confirman el modelo de desarrollo de las otras sociedades medidas con este estudio. Mientras la mayor parte de las sociedades en las 5 mediciones desde 1980 hasta 2006 se han movido a lo largo de la diagonal desde la restricción a mayores grados de elección, GRAFICO 2 aumentando simultáneamente la autoexpresión de cada cual, al mismo tiempo que la racionalidad de sus 
decisiones seculares; América Latina se mueve hacia mayores grados de autoexpresión, reafirmando sus valores tradicionales.

El desarrollo económico -lejos de producir mayores grados de racionalidad- produce una preafirmación de las culturas, las tradiciones, y los valores existentes. En los últimos 2 años desde la ola de elecciones que empezó en diciembre del 2005, América Latina ha visto el surgimiento del multiculturalismo, la defensa de las culturas autóctonas, y la inclusión de las primeras naciones a la democracia. Los datos 2007 muestran cómo las naciones que tienen mayores niveles de transformación, como Ecuador y Bolivia, son aquéllas que más democratización acusa

En efecto si hacemos un zoom sobre América latina en el GRAFICO 1, vemos, a modo de ejemplo, como han evolucionado los distintos países de la región, donde lo que se confirma es que la dirección general de América Latina no es la esperada por la hipótesis que se sostiene con las sociedades fuera del mundo hispano.

WORLD VALUE SURVEY CHILE, ARGENTINA, MEXICO 1980 - 2006

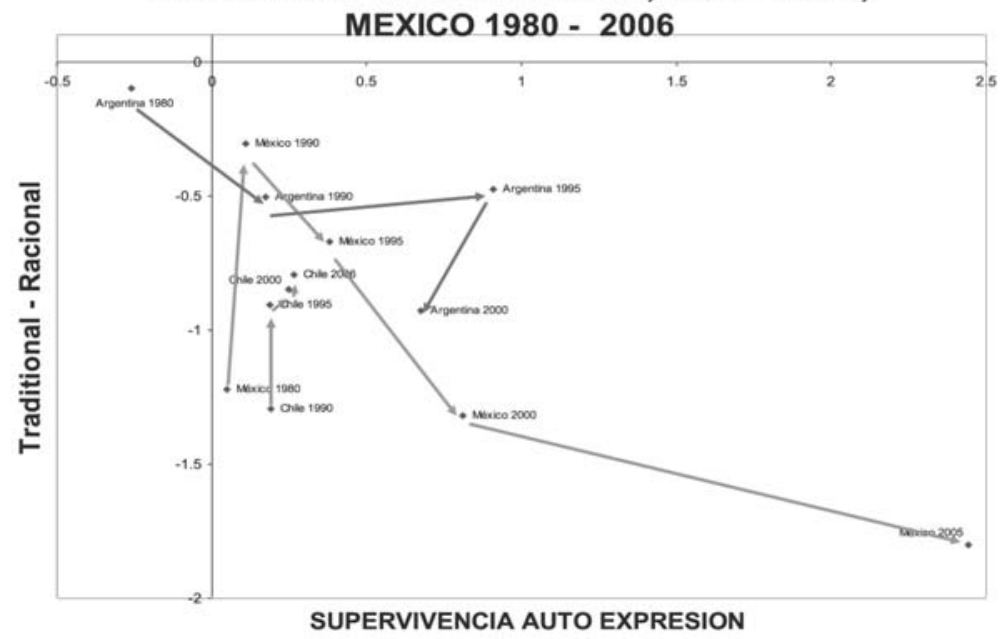

En el caso de Chile, este es el único país de la región que se mueve en el sentido del modelo hacia mayores grados de elección, cambiando simultáneamente sus valores hacia mayores niveles de racionalidad y autoexpresión. Este cambio es, como muestra el grafico, muy limitado al compararse con Argentina y México, donde el modelo acusa el impacto de la crisis argentina en el año 2000.

\section{Conclusión: La democratización segmentada}

El cambio valórico que ha sufrido Chile desde la inauguración de la democracia en 1990 ha producido una sociedad segmentada en su acceso a la libertad y a la igualdad. Lejos de haber sido capaces de abrir la sociedad hacia mayores grados de interacción 
entre todos, la sociedad chilena ha mantenido la estructura social original, donde la vida de cada cual esta bastante determinada por el lugar donde nace. Cerca de tres de cada diez personas lograrán salir del lugar donde nacieron en esta generación presente, con una movilidad social limitada y ciertamente no acorde con el crecimiento económico del país. A la tasa de crecimiento que hemos tenido en estas dos décadas donde se ha mas que duplicado el ingreso per capita de la población, este no ha logrado acelerar la tasa de movilidad social, implicando que el dinero adicional se acumula entre los mismos y no entre muchos mas. Se incorporan de a poco nuevos integrantes de la sociedad formal y prospera donde reina el acceso al mercado, a los bienes políticos, al poder, a la información y a mayores grados de igualdad. Se podría estimar en un 40\% esa porción de chilenos, con un cálculo holgado de la actual movilidad social.

En el otro lado del espectro se encuentra la mayor parte de los chilenos, aproximadamente un 60\%, quienes no logran movilidad social, ni tampoco han duplicado su ingreso o mejorado su condición social a la velocidad del país, sino por debajo de ella. Para ellos hay menores grados de acceso a la democratización, menor acceso a los bienes políticos, económicos e información, al tiempo que mayores grados de desigualdad y discriminación.

El cambio valórico que se produjo en Chile con motivo de la vuelta a la democracia entre 1990 y 1994, es el mas fuerte del que tenemos registro por medio de encuestas. Desde 1994, Chile ha crecido más que lo que ha cambiado valóricamente. Se han enfatizado mas los valores de la autoexpresión que aquellos de la racionalidad.

Los cambios producidos por el desarrollo económico quedan reflejados en la comparación entre los dos censos 1992 -2002, y están ampliamente documentados. Ellos son los cambios inevitables de los que habla Marx. Esos son los que denostan los conservadores que le temen al cambio. El descenso en la fertilidad es un cambio inevitable, ante los cuales la sociedad chilena no puede oponer resistencia.

Hay otros cambios donde sí se opone resistencia como por ejemplo la ley de divorcio. Si bien en 17 años se duplicó el apoyo al divorcio, este se demoró 8 años en ser aprobado en el parlamento. La reciente disputa sobre la píldora del día después es un buen ejemplo de la resistencia al cambio del las cosas mas oscuras de la modernidad, las cosas que desmantelan el orden previo. La píldora del día después es propia de una sociedad más abierta, más tolerante, más racional que la sociedad chilena. Es por ello que la resistencia a su instalación no llama la atención si se mira este modelo. De acuerdo a ello, en unos 50 años más esta tendría aceptación mayoritaria, así como el aborto. 
La sociedad chilena no alcanza cambios valóricos culturales fundamentales para ser desarrollado:

1.- El primero de los cambios no logrados es un mayor grado de democratización, que implica mayor tolerancia a la diversidad, mayor pluralidad y respeto a las minorías. Es la actitud ante la autoridad, la obediencia, el peso de las costumbres entre las que está la costumbre de discriminar. Mientras ello no cambie, seguirá el miedo a disentir que embarga lo políticamente correcto del discurso individual, que complace la costumbre de ir detrás de la corriente dominante. Se aprueba lo que esta "en boga". La demanda de "mano dura" y "don de mando" hacia la primera mujer presidente no es sino una expresión de ese valor predominante de la autoridad jerárquica. La democracia implica la horizontalizacion del poder que en Chile no ha sucedido.

2.- El segundo de los cambios no logrados es el del desmantelamiento de la desconfianza que embarga lo público y lo privado. Llama la atención la burocratización de los privados que replican la cultura de desconfianza del Estado, con la sobre certificación. Intente usted. tener un crédito en un banco y verá lo que es una sólida burocracia sobre certificada. El contraste con un banco europeo es infinito, donde la sola firma en un pedazo de papel es suficiente. Quizás sea ese el mayor escollo de nuestro crecimiento. Las barreras culturales de la desconfianza en el acceso al crédito. No se han superado los traumas del pasado.

3.- El tercero de los cambios no logrados es el desmantelamiento de la discriminación por el origen de cada cual. El mayor escollo a un trato por igual, es cada cual, que estratifica y discrimina a sus conciudadanos según su origen y color de la piel. Una estilista española lo resumía magistralmente diciendo ".” Las chilenas tienen complejo de India, todas quieren teñirse de rubias". ¿Es ello un escapismo a la discriminación? La discriminación es una de las bases de la desconfianza. Un hito cultural que ha permanecido sin cambio en casi dos décadas.

4.- El cuarto de los cambios no logrados es el de la movilidad social. La prosperidad no es democrática. Todos tienen un poco más, sin impacto redistributivo.

La prosperidad no democrática es la mejor manera de expresar el punto de desarrollo en que se encuentra Chile en el año 2007. La democratización pendiente requiere abordar los cuellos de botella valóricos que nos retienen. El gobierno de Michelle Bachelet simboliza la tensión entre la demanda de cambio y la resistencia al cambio. 